\title{
Bioética e intimidad. La tutela de los datos personales biomédicos
}

ANTONIO-ENRIQUE PEREZ LUÑO

Catedrático de la Facultad de Derecho, Universidad de Sevilla

\section{SUMARIO:}

1. Intimidad y protección de datos personales

2. Los datos personales bimédicos

3. Legislación relativa a la tutela de la intimidad respecto a datos sanitarios

4. Aproximación a la jurisprudencia del Tribunal Constitucional

5. Apostillas sobre la comunicación de datos personales sanitarios en Internet

6. Conclusión: la tutela de los datos personales biomédicos en la era biotecnológica

\section{INTIMIDAD Y PROTECCIÓN DE DATOS PERSONALES}

Parece ser tributo inevitable de los conceptos y categorías más recurrentes en la teoría jurídica adolecer de un déficit de intensión conceptual proporcionalmente inverso a su extensión de uso. Esa tendencia puede predicarse de la noción de intimidad, utilizada en la nuestra más

(*) Deseo agradecer a los Profesores Rafuel González-Tablas, Alvaro Sánchez Bravo y Enrique Sánchez Jiménez, su atenta lectura critica y estimulantes sugerencias, que me han sido de gran provecho intelectual para la slaboración de este trabajo. 
que en cualquier otra época, pero con tal grado de indeterminación y equivocidad que dificultan precisar su sentido y su alcance jurídico. A ello se refería Vitalis al considerar a la intimidad como un concepto indescifrable (1981,151); o Hixson que achacaba a la asiduidad y amplitud de su empleo el que fuera imposible precisar su contenido (1987, 60 ss.). Esas ambigüedades significativas gravitan sobre la propia posibilidad y eficacia de los cauces jurídicos de protección de los bienes o valores que se pretenden tutelar bajo ese incierto término de referencia.

La intimidad no tiene un solo perfil como los antiguos relieves de Egipto o Asiria; al abordar su análisis se suceden una serie de bifurcaciones o dilemas. El dilema preliminar y básico a que debe hacer frente cualquier consideración jurídica de la intimidad es, precisamente, el de si es posible un concepto jurídico de intimidad. El término intimidad ahonda su raíz etimológica en el vocablo latino intimus, que evoca la idea de lo más interno o recóndito. Intimidad será la interioridad de la persona, como disposición peculiar del ser humano a la introspección, a lo recóndito y secreto. No en vano el término germano " $\mathrm{Ge}$ heim", es decir, lo secreto o reservado, evoca etimológicamente aquello que se encierra en el hogar; y tiene su correlato en el adagio inglés: "My home is my Castle". Desde esas premisas se desemboca inevitablemente en la identificación de la intimidad con la soledad y el aislamiento. En el célebre trabajo pionero The Right to Privacy, publicado el año 1890, en el que Samuel Warren y Louis Brandeis sientan las bases técnico-jurídicas de la noción de privacy, la conciben como un derecho a la soledad, como la facultad "to be let alone"; como la garantía de los individuos frente a cualquier invasión del sagrado recinto de su vida privada y doméstica (1890-91,193). De modo análogo, en su excelente Ensayo sobre la vida privada, cuya primera edición data de 1935, Manuel García Morente no vacila en sostener que: "La soledad es la forma más perfecta de la vida privada"(1992,49. Aborda también el concepto de lo íntimo, aunque con menor enjundia y profundidad, Bejar, 1988, 141 ss.). 
Desde ese ángulo, lo mismo para García Morente que para Ortega, la intimidad tiene como condición esencial el ensimismamiento; "el poder que el hombre tiene de retirarse virtual y provisionalmente del mundo y meterse dentro de si'". Este concepto de intimidad, que corresponde a lo que en la terminología heideggeriana popularizada en la filosofía del Derecho por Werner Maihofer representa la esfera del Selbstsein, sitúa la definición de la intimidad en el plano de la autoconsciencia, la identidad y la propia personalidad del individuo (Maihofer, 1968, 10 ss.). La intimidad, en esta acepción, "requiere para ser vivida ese fondo de insobornable personalidad" (García Morente, 1992,36).

Esa noción filosófica de intimidad ha sido progresivamente descartada en sus proyecciones jurídicas. En éstas no cabe operar con una noción de intimidad circunscrita a un "ius solitudinis". La elaboración jurídica de la privacidad ha tendido a trasportarla desde la esfera de la soledad a la de las relaciones sociales. Un concepto de la intimidad que no trascendiera al ámbito de la alteridad y del Mitsein, es decir, a la esfera de la "convivencia", carecería de relevancia jurídica. El problema de la intimidad se plantea con respecto a las manifestaciones o incidencias exteriores de o en nuestra vida privada, cuyo ejercicio se halla garantizado jurídicamente. Eso muestra que el problema de la intimidad como tal o es un problema jurídico o no existe; se trata de un problema jurídico que, por supuesto, tiene una raíz filosófica, pero que en el momento en el que incide en relaciones con los demás, o sea, cuando empieza a ser problemático deviene jurídico.

Estas circunstancias conducen a un insoslayable dilema conceptual: si se desea mantener fidelidad a la significación primigenia de la intimidad hay que radicarla en la esfera del "fuero interno", de la soledad, el ensimismamiento y el autoconfinamiento personal, pero entonces ese concepto corre el riesgo de situarse en el plano de lo inefable y carece de cualquier operatividad jurídica; si, por el contrario, tomamos como punto de referencia sus implicaciones y proyecciones intersubjetivas en el ámbito del "fuero externo" se cierne la amenaza de deformar la inti- 
midad, de cosificarla, de diluirla en un conjunto de tópicos sociales y en suma de alienar la intimidad en su antónimo, es decir, en la "alteración"; o sea, en que deje de ser sí misma para verse traída, llevada y tiranizada "por lo otro" (Ortega y Gasset, 1983,7,83).

¿Existe algún punto de mediación entre estas polaridades de un dilema, en apariencia, irreductible? Personalmente estimo que sí. La concepción de la intimidad como aislamiento y ensimismamiento no es necesariamente incompatible con sus proyecciones sociales, si se la reputa como un primer momento de su proceso formativo. Ese "intus " o fase solitaria e interna de la intimidad se hallaría conformado por ideas, que reclamarían su ulterior exteriorización en acciones. El ensimismamiento confinado en sí mismo, sólo sería capaz de fabricar mundos interiores, fantasmagorías condenadas a degenerar en puro solipsismo. La dimensión interna y ensimismada de la intimidad para realizarse plenamente precisa extrovertirse; porque, por decirlo con palabras de García Morente, "la convivencia nos es indispensable,... nuestra vida para vivir, necesita apoyarse en otras vidas" $(1992,50)$. Esa apertura a la convivencia se ejercita a través de las formas de comunicación y de lenguaje que se integran y socializan lo más íntimo de nuestro ser y, en ese sentido, concluye Ortega que: "El ser más íntimo de cada hombre está ya informado, modelado por una determinada sociedad" (1983,7,254). Entre otras cosas, porque la propia noción de intimidad es una categoría cultural, social e histórica. Esa dimensión abierta, social y dinámica de la intimidad se halla corroborada, en su proyección jurídica, desde premisas doctrinales, legislativas y jurisprudenciales.

1) En el ámbito doctrinal se ha pasado desde una concepción cerrada y estática de la intimidad a otra abierta y dinámica. El contenido de la primera, identificada con el "ius solitudinis", podía ser perfectamente explicada con las modalidades deónticas de Wesley Newcomb Hohfeld (1913,16 ss); es decir como pretensión, libertad, poder e inmunidad a disponer de un ámbito de vida personal sustraído a cualquier tipo de intromisiones perturbadoras o, simplemente, no deseadas. Pero en la ac- 
tualidad esa visión cerrada y defensiva de la intimidad ha sido sustituida por una concepción activa y dinámica en la que la intimidad se contempla como la posibilidad de conocer, acceder y controlar las informaciones que conciernen a cada persona.

En nuestra época, la doctrina ha trasladado el centro de gravedad o, si se quiere, la delimitación conceptual del derecho a la intimidad desde la facultad al aislamiento al poder de control sobre las informaciones que son relevantes para cada sujeto. Un testimonio elocuente de estos nuevos perfiles de la intimidad se desprende del planteamiento de Adalbert Podlech. A su entender, la intimidad, más que un estado de autoconfinamiento, supone una determinada calidad de la relación con los otros. Se trata, por tanto, de una condición o calidad social de la persona, que es objeto de tutela constitucional en la medida en que ésta puede tener legítimo derecho a no revelar a los demás determinados aspectos de sus relaciones con otras personas, que el titular del derecho juzga deben permanecer en un plano reservado o privado. Precisamente esa facultad de elección de la persona sobre la revelación o no de informaciones que directamente le conciernen constituye el núcleo de la autodeterminación informativa (informationelle Selbstbestimmung) en cuanto aspecto básico de la intimidad (Podlech, 1984, 341 ss.; Denninger, 1987; Garriga, 1999; Lucas Murillo de la Cueva, 1990; Pérez Luño, 1989). Esas nuevas facetas de la intimidad propias de las sociedades avanzadas requieren nuevos instrumentos de tutela jurídica. La defensa de la intimidad respecto al tratamiento automatizado de datos personales se halla garantizada por un cauce procesal denominado habeas data. Al tradicional habeas corpus corresponde en las sociedades tecnológicas del presente el habeas data, que cumple una función paralela, en el seno de los derechos humanos de la tercera generación, a la que en los de la primera generación correspondió al habeas corpus respecto a la libertad física o de movimientos de la persona. No es difícil, en efecto, establecer un marcado paralelismo entre la "facultad de acceso" en que se traduce el habeas data y la acción exhibitoria del habeas corpus (Pérez Luño, 1992 a). 
2) La legislación actual en materia de intimidad muestra una creciente decantación hacia la componente externa y social de este derecho. Quizás la manifestación más rotunda de esta tendencia haya hallado cauce expresivo en la Ley Orgánica 1/1982 de 5 mayo, de Protección civil del derecho al honor, a la intimidad personal y familiar y a la propia imagen. Se afirma en dicha disposición que la tutela civil de la intimidad "quedará delimitada por las leyes y por los usos sociales atendiendo al ámbito que, por sus propios actos, mantenga cada persona reservado para sí misma o su familia" (art. 2.1). Esa apelación a los usos, quizás la más importante contenida en nuestro ordenamiento jurídico, denuncia la precipitación de los teóricos del Derecho que habían expedido acta de defunción respecto a la normatividad de los usos sociales. El legislador justifica la remisión a los usos como categoría delimitadora de la intimidad por considerar que ésta se halla determinada en forma decisiva "por las ideas que prevalezcan en cada momento en la sociedad" (Exposición de Motivos). La propia decantación en el Derecho comparado desde la tutela jurídica de la intimidad, a la de la privacidad que pretende traducir a las culturas europeas la noción anglosajona de privacy, así como a las categorías de los denominados "datos personales" y "perfiles de la personalidad", que se proyectan sobre un conjunto más amplio y global de relaciones intersubjetivas, reflejan esa tendencia paradójica hacia la "socialización de la intimidad" (Cabezuelo Arenas, 1998).

3) También en el plano jurisprudencial hoy se tiende a abandonar definitivamente la denominada "teoría de las esferas"(Sphärentheorie), que tuve ocasión de exponer en anteriores trabajos sobre la vida privada, y con la que la jurisprudencia constitucional de la República Federal de Alemania había establecido unos cauces para la tutela de la intimidad. Según esta orientación, se puede establecer una protección gradual situando los comportamientos en sucesivas esferas a tenor de su referencia social (Sozialbezug). Se distinguen así: 1) una esfera íntima (Intimsphäre), que corresponde al ámbito más recóndito y secreto de la persona; 2) una esfera privada (Privatsphäre), que hace referencia a la 
dimensión de vida personal y familiar; y 3) una esfera individual (Individualsphäre), que afecta a cuanto define la peculiaridad o individualidad de una persona (nombre, imagen...). A tenor de esta artificiosa distinción, el Bundesverfassungsgericht establecía una intensidad de tutela inversamente proporcional a la dimensión social de la conducta o actividad concernida (Pérez Luño, 1989, 157ss.; 2002, 327 ss.).

Frente a esta construcción abstracta e irreal, se aboga ahora por un sistema de tutela de la intimidad basada no en la "intensidad social" de la conducta, puesto que todo comportamiento, para tener relevancia jurídica, debe poseer una dimensión social, sino en los valores e intereses, públicos y/o privados, que pueden contraponerse al deseo de la persona concernida de mantener sus datos en un plano de reserva. Esa nueva faceta de la intimidad ha hallado nítida expresión en la célebre sentencia de 15 de diciembre de 1983 del Bundesverfassungsgericht alemán sobre la Ley del censo de población (Volkszählungsgesetz), en la que la jurisprudencia germana concibe la intimidad como "autodeterminación informativa" (informationelle Selbstbestimmung), es decir, como la libertad del ciudadano para determinar quién, qué y con qué ocasión (wer, was ,wann, bei welchen Gelegenheit ) puede conocer y/o utilizar datos que le afectan.

En suma, se trata de insistir, como corolario de lo hasta aquí apuntado, que en nuestra época resulta insuficiente concebir la intimidad como un derecho (status negativo) de defensa frente a cualquier intromisión de la esfera privada, sin contemplarla, al propio tiempo, como un derecho activo de control (status positivo) sobre el flujo de informaciones que conciernen a cada sujeto. De ahí que la estrecha conexión que liga el derecho a la autodeterminación informativa con el derecho a la intimidad no tiene por qué traducirse en una concepción individualista de ésta, en la medida en que la propia intimidad ha dejado de ser un privilegio del hombre aislado para devenir en un valor constitucional de la vida comunitaria.

Estas consideraciones permiten inferir la posibilidad de superar las polaridades dilemáticas de la intimidad en función de tres premisas: $1^{\text {a }}$ ) La pluralidad de manifestaciones en las que la intimidad se manifiesta 
(privacidad/privacy, datos personales, perfil de personalidad, autodeterminación informativa...) no implican una disolución del concepto unitario de intimidad, sino más bien su ampliación y adaptación a las exigencias de un mundo en cambio. No existe, en consecuencia, una pluralidad de conceptos de intimidad, sino un concepto unitario de textura abierta, plural, dinámica y globalizadora.

$2^{\text {a) }}$ La metamorfosis del concepto de intimidad desde la esfera intrasubjetiva del ensimismamiento a la intersubjetiva del control de datos personales, no ha significado la pérdida de su función tutelar de los valores de la personalidad. El derecho a la intimidad trata siempre de defender facultades de autodeterminación del sujeto, pero no de un sujeto aislado irreal y abstracto, producto de una antropología individualista, sino del ciudadano concreto que ejerce su intimidad en el seno de sus relaciones con los demás ciudadanos y con el poder público.

$\left.3^{a}\right)$ Todo ello permite superar una concepción tautológica y circular de la intimidad en función de remisiones "autopoiéticas", a la introspección, la soledad y el ensimismamiento y sustituirla por una noción abierta, dinámica y proyectiva. Así, se supera el dilema entre una intimidad interna y auténtica y una intimidad externa alienada, porque la dimensión interna y su exteriorización son dos momentos complementarios e insoslayables.

\section{LOS DATOS PERSONALES BIMÉDICOS}

Las proyecciones sociales del derecho a la intimidad se han visto corroboradas en todo cuento concierne a la esfera de las informaciones relativas a los datos sobre la salud. Del mismo modo que una de las grandes tensiones jurídicas de la intimidad es la que afecta a su confrontación con el derecho a la libertad de expresar y recibir informaciones, también se plantea una insoslayable antítesis entre el derecho a la intimidad y el derecho a la salud. 
Como se ha indicado, la intimidad aparece hoy como un derecho cifrado en la información, acceso y control de los datos personales que conciernen a los titulares de derechos fundamentales (habeas data). En el seno de esos datos ocupan un lugar relevante, hasta el punto de considerarse como informaciones especialmente sensibles, todos los datos que hacen referencia a la salud de cada persona. Desde la perspectiva de la tutela del derecho a la intimidad cabría admitir la existencia de un derecho de información, acceso y control por parte de cada ciudadano a su historial clínico (habeas data biosanitario). En el seno de una sociedad tecnológicamente avanzada cada sujeto va forjando, desde su nacimiento hasta su muerte, un amplio y, en ocasiones, complejo y prolijo, historial de informaciones médicas. En la medida en que la asistencia sanitaria se ha convertido en uno de los derechos sociales más importantes cuya tutela exigen los miembros de las sociedades avanzadas, se ha ampliado de modo muy considerable el número de datos médicos relativos a cada ciudadano. Podría incluso afirmarse que uno de los parámetros para medir el grado de desarrollo de un Estado sería el de la amplitud de informaciones relativas a la salud de sus ciudadanos (cfr.: Martínez Calcerrada, 1986; Rodríguez del Pozo, 1994).

Esas informaciones pueden ser hoy exhaustivamente procesadas, almacenadas y transmitidas gracias al desarrollo de la informática. Pero ese desarrollo tecnológico supone, al propio tiempo, un grave peligro de violación del carácter íntimo de tales datos.

La tensión surge, precisamente, de la exigencia de los poderes públicos de utilizar la transmisión de esos datos médicos, especialmente de los que hacen referencia a enfermedades contagiosas, o de aquellos que pueden ser utilizados para el desarrollo de avances en la investigación científica y el deseo de los ciudadanos de mantener un control sobre las informaciones que les conciernen.

La legislación y la jurisprudencia de los Estados de derecho con un importante desarrollo tecnológico tiende a establecer una ponderación de bienes, de modo que los avances médicos no supongan una agresión 
al derecho a la intimidad, pero sin consagrar como absoluto un derecho al control de los datos personales que impidiera hacer efectivo el derecho a la salud.

El derecho a la salud, en cuanto derecho social, es decir, en cuanto un derecho del que deben beneficiarse cuantos integran una comunidad política, requiere que no se establezcan cortapisas insalvables que puedan menoscabar su desarrollo. Un desarrollo que se manifiesta, básicamente, en dos esferas: la primera tendente a prevenir, tratar y erradicar las enfermedades infecciosas y contagiosas; y la segunda referida a la necesidad de no crear obstáculos que impidan el desarrollo de investigaciones médicas que tiendan a prolongar la vida y la calidad de la vida, limitando incluso las posibilidades de una disposición absoluta de la misma por parte de los ciudadanos (cfr.: Marcos del Cano, 1999; Sánchez Jiménez, 1999). En ambos casos, suele ser necesario contar con numerosos datos personales concretados en las historias clínicas que sirven de base para la experimentación. Dichos datos, en ocasiones, pueden ser utilizados de forma anónima y con plenas garantías para la intimidad de los afectados. Pero, en otros supuestos, la eficacia de la investigación médica exige el poder elaborar y transmitir datos personales identificados siendo este el supuesto límite de tensión entre el derecho a la intimidad y el derecho a la salud. En la legislación y la jurisprudencia española se pueden detectar algunos supuestos que permiten ilustrar los términos de la tensión apuntada (cfr.: Sánchez Carazo, 2000; Sánchez-Caro, 2001).

\section{LEGISLACIÓN RELATIVA A LA TUTELA DE LA INTIMIDAD RESPECTO A DATOS SANITARIOS}

En el ordenamiento jurídico español existen una serie de normas dirigidas a garantizar el derecho a la intimidad de los ciudadanos con respecto a las informaciones referentes a sus datos sanitarios. Alguna de es- 
tas normas suponen la incorporación a nuestro sistema jurídico de Declaraciones y Tratados internacionales, que al haber sido ratificados por España y publicados en el BOE han pasado a formar parte de nuestro Derecho interno, a tenor de cuanto dispone el artículo 96.1 de la Constitución Española.

Entre estos textos, debe hacerse mención al Convenio para la protección de los derechos humanos y la dignidad del ser humano con respecto a las aplicaciones de la Biología y la Medicina (Convenio relativo a los derechos humanos y la biomedicina), hecho en Oviedo el 4 de Abril de 1997 y ratificado el 23 de Julio de 1999 (BOE de 29 de Octubre de 1999). A este Convenio se le añadió un Protocolo adicional hecho en París el 12 de Enero de 1998, ratificado el 7 de Enero de 2000 (BOE de 1 de Marzo de 2001). El Protocolo adicional de este Convenio del Consejo de Europa, reviste especial importancia y actualidad, porque prohibe la clonación de seres humanos (cfr. García San José, 2002).

Por lo que respecta a la intimidad de los datos sanitarios, el artículo 10 dispone lo siguiente, bajo el título "vida privada y derecho a la información": "l. Toda persona tendrá derecho a que se respete su vida privada cuando se trate de informaciones relativas a su salud. 2. Toda persona tendrá derecho a conocer toda información obtenida respecto a su salud. No obstante, deberá respetarse la voluntad de una persona de no ser informada. 3. De modo excepcional, la ley podrá establecer restricciones, en interés del paciente, con respecto al ejercicio de los derechos mencionados en el apartado 2".

Por otro lado, el artículo 26, bajo el título de restricciones al ejercicio de los derechos, dispone lo siguiente: "l. El ejercicio de los derechos y las disposiciones de protección contenidos en el presente Convenio no podrán ser objeto de otras restricciones que las que, previstas por la ley, constituyan medidas necesarias, en una sociedad democrática, para la seguridad pública, la prevención de las infracciones penales, la protección de la salud pública o la protección de los derechos y libertades de las demás personas". 
El Convenio entró en vigor para España el 1 de enero de 2000, de conformidad con lo previsto en su artículo 38.

Entre las Leyes Orgánicas que desarrollan el artículo 18 de la Constitución española, que consagra el derecho a la intimidad, debe mencionarse la Ley Orgánica de Protección Civil del Derecho al Honor, a la Intimidad Personal y Familiar y a la Propia Imagen, que regula lo que se entiende por intromisiones ilegítimas a dichos derechos y delimita el ámbito de protección civil de la intimidad (Ley Orgánica 1/82, de 5 de Mayo).

Especial importancia reviste la norma que desarrolla el artículo 18.4 de la CE. Se trata de la Ley Orgánica de Protección de Datos de Carácter Personal 15/1999, de 13 de Diciembre (LOPRODA). Esta Ley establece en su artículo 8, la regulación de los "datos relativos a la salud". Se prescribe, en dicho precepto: "Sin perjuicio de lo que se dispone en el art. 11 respecto de la cesión, las instituciones y los centros sanitarios públicos y privados y los profesionales correspondientes podrán proceder al tratamiento de los datos de carácter personal relativos a la salud de las personas que a ellos acudan o hayan de ser tratados en los mismos, de acuerdo con lo dispuesto en la legislación estatal o autonómica sobre sanidad".

Por su parte, el artículo 11 , referido a la "comunicación de datos", establece que: "1.Los datos de carácter personal objeto del tratamiento sólo podrán ser comunicados a un tercero para el cumplimiento de fines directamente relacionados con las funciones legítimas del cedente y del cesionario con el previo consentimiento del interesado. 2.El consentimiento exigido en el apartado anterior no será preciso: f) "Cuando la cesión de datos de carácter personal relativos a la salud sea necesaria para solucionar una urgencia que requiera acceder a un fichero o para realizar los estudios epidemiológicos en los términos establecidos en la legislación sobre sanidad estatal o autonómica" (sobre el alcance y significado de esta norma, cfr. Pérez Luño, 2001 a y b).

De acuerdo con la normativa española sobre protección de datos médicos, aquí reseñada, cuando un paciente facilita sus datos a un profe- 
sional sanitario para que éste forme su ficha médica o en caso de ingreso hospitalario, puede exigir al médico que le informe sobre que va a pasar con esos datos. El paciente debe ser informado de modo expreso, preciso e inequívoco que sus datos van a ser recogidos en un fichero, de la finalidad de la recogida y de los destinatarios de los mismos.

Así mismo, el paciente puede ejercitar los derechos de acceso, rectificación, cancelación y oposición, y para ello deberá ser informado de la identidad del responsable del tratamiento y de la dirección del mismo. El tratamiento de estos datos es totalmente reglamentario siempre que se realice con fines asistenciales y con el expreso consentimiento del afectado o autorización legal basada en razones de interés general.

Respecto al Insalud existe una Circular 9/97 de 9 de Julio: Instrucciones del Insalud sobre seguridad y protección de datos, que establece la obligación de informar sobre la existencia de un fichero, la finalidad de la recogida, del carácter obligatorio o facultativo de la recogida de datos y de la existencia de cesión o transferencia internacional de datos.

Asimismo, conviene aludir a cuanto dispone la Ley sobre Reproducción Asistida Humana, Ley 35/1988, de 22 de Noviembre, en particular los artículos 2.5, 5 y 8.3. En dichas normas se establece el carácter de contrato secreto de la donación de gametos y preembriones para las finalidades autorizadas por dicha ley y el anonimato de la donación, hasta el punto de que los hijos nacidos tienen derecho a obtener información general de los donantes que no incluya su identidad, correspondiendo igual derecho a las receptoras de los gametos. Sólo excepcionalmente, en circunstancias extraordinarias que comporten un comprobado peligro para la vida del hijo, o cuando proceda con arreglo a las leyes procesales penales, puede revelarse la identidad del donante, siempre que dicha revelación sea indispensable para evitar el peligro o para conseguir el fin legal propuesto, si bien la revelación en dichos casos no implica determinación legal de la filiación. En todo caso, el mencionado carácter restringido de la revelación no implica publicidad de la identidad del donante. 
La Ley 30/1979, de 27 de Octubre, sobre Extracción y Trasplante de órganos. En particular el artículo $4 \mathrm{~d}$, garantiza el anonimato del receptor y con carácter general la identificación del donante.

La Ley Orgánica de Medidas Especiales en Materia de Salud Pública, que indirectamente admite la posibilidad de revelar información confidencial con la finalidad de controlar las enfermedades transmisibles (Ley Orgánica 3/1986, de 14 de abril, de medidas especiales en materia de salud pública).

La Ley General de Sanidad (Ley 14/1986, de 25 de abril, en particular, los artículos 10.1 y 3 y el artículo 61), reconoce el derecho de todos los usuarios y pacientes a la intimidad y a la confidencialidad de toda la información relacionada con su proceso y con su estancia en las instituciones sanitarias y exige, además, en lo que hace referencia a la historia clínica, que quede plenamente garantizado el derecho del enfermo a su intimidad personal y familiar y el deber de guardar secreto por quien, en virtud de sus competencias, tenga acceso a las historias clínicas. En esta norma no se definen los datos personales sanitarios. No obstante, la Recomendación n ${ }^{0}$ (97)5 de 13 de Febrero de 1997, del Comité de Ministros del Consejo de Europa a los Estados miembros sobre Protección de Datos Médicos, da una definición general de "dato médico" definiéndolo como todo dato personal relativo a la salud de un individuo, incluyendo aquellos que tienen una clara y estrecha relación con la salud y los datos genéticos. Dicha Ley se aplica, por igual, y en lo que aquí concierne, tanto al ámbito público como al privado.

En lo concerniente a la tutela de los datos biomédicos, las disposiciones de la Ley General de Sanidad han sido expresamente derogadas por la Disposición Derogatoria única de la Ley 41/2002, de 14 de noviembre, básica reguladora de la Autonomía del Paciente y de Derechos y Obligaciones en Materia de Información y Documentación Clínica. El Capítulo III de dicha norma contiene un artículo dedicado a la garantía de: El derecho a la intimidad, en el que se prescribe: 
"1. Toda persona tiene derecho a que se respete el carácter confidencial de los datos referentes a su salud, y a que nadie pueda acceder a ellos sin previa autorización amparada por la Ley.

2. Los centros sanitarios adoptarán las medidas oportunas para garantizar los derechos a que se refiere el apartado anterior, y elaborarán, cuando proceda, las normas y los procedimientos protocolizados que garanticen el acceso legal a los datos de los pacientes."

La Exposición de Motivos de esa Ley expresa las circunstancias que han conducido a su promulgación. Se indica, a tal efecto, que en septiembre de 1997, en desarrollo de un Convenio de colaboración entre el Consejo General del Poder Judicial y el Ministerio de Sanidad y Consumo, tuvo lugar un Seminario conjunto sobre información y documenta* ción clínica, en el que se debatieron los principales aspectos normativos y judiciales relacionados con dichas cuestiones. En esa misma época, se constituyó un grupo de expertos a quienes se encargó la elaboración de unas directrices para el desarrollo futuro de este tema. Este grupo suscribió un dictamen el 26 de noviembre de 1997, que ha sido tenido en cuenta en la elaboración de los principios fundamentales de esta Ley.

En la profesión médica han tenido siempre gran importancia los Códigos deontológicos, cuya tradición se remonta al célebre Juramento Hipocrático. Un ejemplo reciente, a escala española de estos textos es el Código de Ética y Deontología médica de la Organización Médica Colegial. Se trata de un texto que fue establecido por la asamblea de presidentes y consejeros de los colegios de médicos y aprobado el 25 de septiembre de 1999. Conviene destacar su capítulo IV bajo la rúbrica "Secreto profesional del médico". Algunos de los artículos recogidos en el código hacen referencia expresa a la tutela de la intimidad de los datos médicos. Así, por ejemplo, el artículo 14 prescribe:

"1. El secreto médico es inherente al ejercicio de la profesión y se establece como un derecho del paciente a salvaguardar su intimidad ante terceros. 
2. El secreto profesional obliga a todos los médicos cualquiera que sea la modalidad de su ejercicio.

3. El médico guardará secreto de todo lo que el paciente le haya confiado y de lo que él haya conocido en el ejercicio de la profesión.

4. La muerte del paciente no exime al médico del deber del secreto".

El artículo 15, señala que: "1. El médico tiene el deber de exigir a sus colaboradores discreción y observancia escrupulosa del secreto profesional. Ha de hacerles saber que ellos también están obligados aguardarlo.

2. En el ejercicio de la medicina en equipo, cada médico es responsable de la totalidad del secreto. Los directivos de la institución tienen el deber de facilitar los medios necesarios para que esto sea posible".

A su vez, el artículo 16, establece: "1 Con discreción, exclusivamente ante quien tenga que hacerlo, en sus justos y restringidos límites y, si lo estimara necesario, solicitando el asesoramiento del Colegio, el médico podrá revelar el secreto en los siguientes casos":

a) Por imperativo legal.

b) En las enfermedades de declaración obligatoria.

c) En las certificaciones de nacimiento y defunción.

d) Si con su silencio diera lugar a un perjuicio al propio paciente o a otras personas, o a un peligro colectivo.

e) Cuando se vea injustamente perjudicado por causa del mantenimiento del secreto de un paciente y éste permita tal situación.

f) Cuando comparezca como denunciado ante el Colegio o sea llamado a testimoniar en materia disciplinaria.

g) Cuando el paciente lo autorice. Sin embargo, esta autorización no debe perjudicar la discreción del médico, que procurará siempre mantener la confianza social hacia su confidencialidad".

Merece, por último ser también citado el artículo 17, que indica: "l. Los sistemas de información médica no comprometerán el derecho del paciente a la intimidad". 
De las distintas normas reseñadas aquí, así como de aquellas otras que conforman el Derecho comparado de la tutela de los datos personales sanitarios, se desprenden algunos principios básicos que, en síntesis, pueden cifrarse en los siguientes:

1) Principio de sensibilidad. Los datos personales concernientes a la salud se consideran un capítulo cualificado de las informaciones "sensibles", es decir, de aquellas que deben ser objeto de una tutela jurídica reforzada por afectar al núcleo mismo del derecho a la intimidad de las personas.

2) Principio de información y control. Debe reconocerse a toda persona, como facultades que dimanan de su derecho a la intimidad, la posibilidad de conocer y acceder a cuantas informaciones sobre su salud se hallan registradas en los distintos tipos de archivos médicos. Asimismo, todos los ciudadanos deben estar facultados para ejercer un control sobre los datos sanitarios que les conciernen. Tal control se desglosa en las facultades de conocimiento de la finalidad para el que tales informaciones son registradas, las posibilidades de su transmisión a terceros, las garantías de su almacenamiento y seguridad frente a cualquier tipo de manipulación, el consentimiento previo para su uso...

3). Principio de solidaridad. Las informaciones personales sanitarias conciernen prioritariamente a los individuos de quienes las mismas proceden, pero poseen también un interés social y colectivo. En el Estado social de derecho existe un interés de los poderes públicos por promover el derecho a la salud de todos los ciudadanos. Por ello, los datos sanitarios de cada ciudadano constituyen una porción integrante del perfil de la salud colectiva de la sociedad. Se advierte, por tanto, un interés público en salvaguardar la salud de cada ciudadano en cuanto miembro de la comunidad. De otro lado, cuando se trata de enfermedades epidemiológicas y/o contagiosas, existe un interés público en la utilización y transmisión de los datos personales de los afectados necesarios para prevenirlas o erradicarlas. En esos supuestos el principio de solidaridad exige el sacrificio del derecho a la intimidad de esos datos personales sanitarios en función de la garantía del derecho a la salud de la colectividad. 
4) Principio de la restricción menor posible. En la teoría de la interpretación de los derechos fundamentales se invoca, por parte de la jurisprudencia constitucional de los Estados de Derecho, el principio a tenor del cual cuando una libertad debe ser limitada por concurrir con otra libertad o derecho fundamental que se considera prevaliste, el sacrificio de la libertad afectada debe ser el mínimo posible. Por esta razón, en aquellos casos en los que el derecho a la intimidad de los datos personales sobre la salud deba ser restringido por razones de solidaridad, deberá limitarse tal restricción a cuanto sea estrictamente necesario. Ello implica la exigencia de salvaguardar cuantas garantías sean posibles para evitar la indefensión o el sacrificio absoluto de la intimidad de las personas afectadas.

Un aspecto de incuestionable importancia para poder calibrar el grado de eficacia de las normas de tutela de la privacidad de los ciudadanos en la esfera médica, se halla constituido por la jurisprudencia. En este aspecto, en lo que hace relerencia a nuestro ordenamiento jurídico, tienen especial relevancia las decisiones referidas a esta materia procedentes del Tribunal Constitucional. Sin pretensión alguna de exhaustividad, se pueden mencionar algunos casos de incuestionable interés.

Una decisión del TC, que adquirió notable celebridad fue la referente al amparo interpuesto por Isabel Pantoja contra la comercialización de un vídeo que reproducía imágenes de la cogida y agonía de su marido, el torero Paquirri, el Tribunal Constitucional anula una sentencia anterior del Tribunal Supremo en la que se sustentaba que la cogida, agonía y muerte del torero no formaban parte de su intimidad (STS de 28, octubre 1986). Frente a esta tesis el Tribunal Constitucional estima que ha de rechazarse que las escenas vividas dentro de la enfermería formasen parte del espectáculo taurino, añadiendo además que: "en 
ningún caso pueden considerarse públicos y parte del espectáculo las incidencias sobre la salud y vida del torero, derivada de las heridas recibidas, una vez que abandona el coso, pues ciertamente ello supondría convertir en instrumento de diversión y entretenimiento algo tan personal como los padecimientos y la misma muerte de un individuo, en clara contradicción con el principio de dignidad de la persona que consagra el art.10 de la C.E."'(STC. 231/1988, FJ 8).

Merece también ser destacada como un ejemplo decidido de tutela de los datos personales sobre la salud, la sentencia en la que se otorgó el amparo en defensa a la intimidad de un enfermo del sida de quien la prensa había publicado datos que permitían su identificación. Se dice en dicha sentencia que: "la intimidad personal y familiar es, en suma un bien que tiene la condición de derecho fundamental (art.18.1 de la Constitución) y sin el cual no es realizable, ni concebible siquiera, la existencia en dignidad que a todos quiere asegurar la norma fundamental (art.10.1)" (STC 20/1992 FJ 3).

Resulta también muy ilustrativa, en orden a calibrar la sensibilidad del TC respecto a la tutela de la intimidad de los datos sanitarios, la STC $232 / 1993$, en la que no se admitió el amparo interpuesto por la revista "Cambio 16", la cual había sido condenada previamente por el TS por haber publicado un artículo en el que en grandes titulares se aludía a: "El prepucio del Marqués". En esta sentencia se alude a la presentación del libro Las malas compañías, por parte de los periodistas Giménez Arnau y López Robers. En dicho acto el Sr. Giménez Arnau relató públicamente que el Administrador del Marqués de Urquijo, se vio obligado a realizar una serie de curas en el prepucio del Marques, quien padecía de un herpes en esa íntima y delicada zona de su anatomía. El TC entendió que esa información representaba un grave atentado para el honor y la intimidad de las personas, en aspectos relativos a su salud, sin que ello tuviera ningún interés público que pudiera justificarlo.

Asimismo, debe ser reseñada la STC 202/1999, en la que, con ocasión de la delegación a un trabajador de la cancelación de sus datos mé- 
dicos en un fichero informatizado de una entidad de crédito sobre bajas por incapacidad temporal, se apreció que el almacenamiento sin cobertura legal en soporte informático de los diagnósticos médicos del trabajador sin mediar su consentimiento expreso constituía una desproporcionada restricción del derecho fundamental a la protección de datos personales.

Aunque no se refieran específicamente a la tutela de la intimidad en la esfera médica, debe aludirse, por su importancia para la protección constitucional de los datos personales en España, a las sentencias del TC $290 / 2000$ y 292/2000, ambas de 30 de noviembre. En la primera se resuelven los recursos de inconstitucionalidad presentados contra la LORTAD (Ley Orgánica de Regulación del Tratamiento Automatizado de los Datos de Carácter Personal) de 29 de octubre de 1992; en la segunda, los recursos de inconstitucionalidad interpuestos contra la LOPRODA (Ley Orgánica de Protección de Datos de Carácter Personal de 13 de diciembre de 1999). No se aborda aquí el análisis pormenorizado de estas Sentencias, por haberlo llevado a cabo en algunas publicaciones anteriores a las que remito (Pérez Iuño, 2001, a y b; id., 2003; vid., también Seoane Rodríguez, 2002).

En estos pronunciamientos se ha ido perfilando una doctrina del TC dirigida a extraer art.18.4 CE, una doble consecuencia en orden al sistema constitucional de los derechos fundamentales: 1) de una parte, un instituto de garantía o derecho instrumental tendente a tutelar el pleno ejercicio de todos los derechos fundamentales, en particular de la intimidad, frente a cualquier abuso informático; 2) de otra, como un derecho autónomo a la libertad informática, entendida como el poder de control de los ciudadanos de las informaciones que les conciernen, y que se desglosa en facultades de información, acceso, rectificación, oposición y cancelación de sus datos personales, que integran la acción de habeas data (cfr. Pérez Luño, 2001 a y b). 


\section{APOSTILLAS SOBRE LA COMUNICACIÓN DE DATOS}

\section{PERSONALES SANITARIOS EN INTERNET}

La era de la informática y de la telemática ha sido la que más decisivamente ha contribuido a que se adquiera la convicción de que el habitat cívico del presente es el de la "aldea global" o, mas exactamente, "el hogar global"; en la medida en que hoy con el acceso a Internet cada ciudadano puede establecer, sin salir de su domicilio, una conversación en tiempo real, sin límites en el espacio ni en las personas.

En estos últimos años se han acelerado, con ritmo creciente, estos procesos de renovación tecnológica que tan profundamente inciden en las relaciones humanas. El influjo de las redes de información y comunicación en los ámbitos jurídicos y políticos, así como en el campo de la medicina, ha determinado que se adquiera consciencia de que nunca como hoy se había sentido tan intensamente la necesidad de concebir los valores y derechos de la persona como garantías universales. De esa exigencia de universalidad se infiere la reivindicación de que los derechos de la persona se tutelen sin discriminación alguna por razones de raza, de lengua, de sexo, de las religiones profesadas o de las convicciones ideológicas (cfr.: Pérez Luño, 2000; Porras del Corral; 1996; Sánchez Bravo, 2001).

Se siente hoy con mayor intensidad que en cualquier etapa histórica precedente, la exigencia de que los derechos y las libertades no se vean comprometidos por el tránsito de las fronteras estatales.

Estos requerimientos vienen impuestos por esos procesos de mutua implicación económica que reciben el nombre de la "globalización"; y porque vivimos en el seno de sociedades interconectadas a escala planetaria, cuyo testimonio más evidente es, la ya mencionada red de uso ineludible y omnipresente que supone Internet.

Las revistas especializadas en temas médicos revelan que cerca de una cuarta parte de las consultas realizadas en buscadores de Internet están relacionadas con la salud. Se cita un estudio de la consultora PWC 
que eleva esta cifra hasta el $40 \%$ de las búsquedas realizadas. Los internautas preocupados por su salud son millones $y$, atendiendo a este interés, muchas empresas han lanzado sus webs y portales médicos con el objeto de satisfacer esta demanda de información sobre cuestiones relativas a la salud.

Los poderes públicos y algunos especialistas alertan de los peligros de las consultas médicas por Internet debido al elevado fraude y la información errónea existente en la red, y, en la materia que aquí es objeto de estudio, por la dudosa confidencialidad de los datos médicos de los paciente que son transmitidos a través de la red.

Millones de personas emplean Internet para consultas relacionadas con la salud o de las enfermedades que les afectan. Foros, chats o páginas webs permiten a los enfermos localizar a otras personas que sufren los mismos males, y aprender juntos a superarla, mejorando de esta forma su estado anímico y su calidad de vida (Odontorret, 2002).

La medicina alternativa también está presente en la Red. El Club de las plantas medicinales tiene su web con sus peculiares consejos en www.geocities.com/yerba2001, mientras que diversas Asociaciones Homeopáticas ofrecen en su web todo tipo de información.

No huelga recordar que cualquier persona puede crear su propia página web, y por lo tanto, dar sus consejos médicos. Por esta razón es recomendable actuar con la máxima cautela antes de ofrecer datos personales sanitarios a portales del ciberespacio, cuya solvencia y garantía de confidencialidad no se halle plenamente asegurada.

La Red es un lugar habitual al que acuden los profesionales sanitarios cuando necesitan conseguir nuevos datos e información. La rapidez de esta nueva tecnología ha permitido que Internet sustituya, en gran medida, a las revistas de medicina como lugar de consulta profesional. Esto es posible por las 35.000 revistas médicas, y cinco millones de artículos sobre medicina, publicados en Internet. Pero a nadie escapa que en el seno de esa ingente cantidad de informaciones y de documentación médica pueden existir datos relativos a la salud de personas iden- 
tificadas o identificables, cuya intimidad en este ámbito se ve agredida o, al menos, amenazada.

En su informe de Julio de 2001 la Comisión de Informática y libertades de Francia, que es un ombudsman especializado en la protección de los derechos fundamentales frente a eventuales abusos informáticos, denunció la práctica ilícita de determinadas empresas farmacéuticas que utilizan datos médicos recabados por entidades aseguradoras, o de páginas web, especializadas en temas de salud, con fines de propaganda comercial. De cuanto antecede se desprende que los portales sobre medicina y salud tienen una presencia destacada y creciente en la red, por lo que se hace necesario tutelar los datos personales médicos de los usuarios de dichos servicio.

Entre los más importantes aspectos de la transmisión de datos médicos en España a través de Internet, debe aludirse al Sistema TAIR (Terminal Autónomo de Identificación de Registros). El TAIR es un terminal de registro y almacenamiento de datos que utilizan los médicos en su consulta. El médico pasa la tarjeta sanitaria del paciente por el lector y éste crea una etiqueta que se pega a la receta que el médico prescribe. En esta etiqueta aparece el CIP (Código de Identificación del Paciente) y el CIAS (Código de Identificación del Área Sanitaria), datos de carácter administrativo, necesarios para la gestión del paciente por el Insalud y para determinar los perfiles de consumo de los usuarios. De esta manera se posibilita el establecimiento de medidas de racionalización del gasto y un mejor control y lucha contra el fraude en la presentación farmacéutica.

Los datos personales del paciente quedan siempre bajo el control del Insalud, pudiendo acceder a ellos también, de forma restringida, las Farmacias y los Colegios Farmacéuticos. La receta pasa a la farmacia, y el licenciado/a pasa el código de barras de la etiqueta por el lector y expide el medicamento, sin conocer datos personales sobre el sujeto, mas que el CIP. En este caso no se produce una cesión de datos puesto que las farmacias no se consideran terceros. 
Las farmacias envían las recetas al Colegio Oficial de Farmacéuticos, los cuales envían los datos a terceras empresas que prestan el servicio de recogida y grabación de estos datos, creando un gran fichero.

Este proceso está regulado por un Convenio de 17 de Noviembre de 1998, suscrito por el Presidente Ejecutivo del Insalud y la Dirección General de Colegios Oficiales de Médicos y Farmacéuticos. Cualquier uso distinto que el Colegio quisiera dar a estos datos necesitaría autorización del Insalud, ya que éste es el responsable del fichero.

Para la existencia de este fichero de titularidad pública era necesario que una norma autorizase su creación, por ello se dictó la Orden $\mathrm{Mi}$ nisterial del Consejo General de Consumo de 21 de Julio de 1994.

Este sistema suscitó dudas sobre la seguridad de la garantía del carácter privado de ese ingente número de informaciones personales sanitarias. Sin embargo, el Director de la Agencia de Protección de Datos (APD) entendió que este procedimiento era conforme a la LOPRODA, ya que se respetaba la intimidad del usuario y la confidencialidad de sus datos médicos.

Especial relevancia, a efectos de la necesaria tutela de la intimidad de los datos personales en ellos almacenados, poseen los FICHEROS CON DATOS SOBRE VIH. En la actualidad existe un fichero nacional, dependiente del Ministerio de Sanidad (Plan Nacional de Sida) en el que se registran los datos de los pacientes enfermos de SIDA (Síndrome de Inmunodeficiencia Adquirida). Se trata de una enfermedad de declaración obligada (EDO), por lo que los médicos han de informar de que tienen un paciente enfermo de SIDA, esta información pasa a las delegaciones provinciales, que la envían a las autoridades autonómicas, que a su vez envían las actualizaciones del fichero al Ministerio de Sanidad.

Los médicos han de informar al paciente de la existencia de este fichero, que contiene su nombre y apellidos, dirección, fecha de nacimiento y fecha de defunción. La finalidad de la existencia de este fichero es el interés general, para seguir un control de la enfermedad. Como quiera que estas informaciones sobre el Sida se transmiten a través de 
la red, las garantías de confidencialidad y de seguridad en la comunicación deben ser reforzadas, dado el carácter especialmente sensible de tales datos y la grave repercusión que para los enfermos concernidos entrañaría la divulgación de los mismos (Portaley, 2002).

El desciframiento del genoma humano ha generado un volumen inmenso de datos que para su correcta elaboración y aprovechamiento exigen la utilización de las nuevas tecnologías informáticas telemáticas. Gracias a la informática y, en particular a Internet se podrá facilitar el trabajo científico y la transformación de los datos en conocimiento (cfr.: Malem Seña, 1995).

Los proyectos de genoma humano han producido en los últimos 3 años la misma cantidad de información que toda la humanidad había generado en los últimos 40.000 años, y esa no es más que la primera fase porque ahora la decodificación del proteoma (la estructura de proteínas asociadas a los genes), está generando más información aún, que no serviría de nada si no se pudiera analizar (ciberafondo, 2002). Esta masa ingente de datos e informaciones que tienen su principal vehículo comunicativo en Internet y que, de modo necesario, hacen referencia a personas, constituyen un reto para las actuales técnicas jurídicas de tutela de los datos sanitarios.

La red, en definitiva, en lo que atañe a los datos personales sanitarios, presenta la misma ambivalencia que en otras esferas de la vida social, cultural y política. En su anverso, constituye un fenómeno de excepcional alcance para reforzar el derecho a la salud, mediante la transmisión en tiempo real de informaciones, investigaciones, diagnósticos tendentes a prevenir, tratar y erradicar la enfermedad. La red representa un instrumento básico para el logro de una medicina cada vez más personalizada y eficaz. Pero, en el reverso de estas virtualidades, Internet supone un riesgo constante de perforación de la intimidad de los datos personales sanitarios. 


\section{CONCLUSIÓN: LA TUTELA DE LOS DATOS PERSONALES BIOMÉDICOS} EN LA ERA BIOTECNOLÓGICA

La revolución tecnológica ha redimensionado las relaciones del hombre con los demás hombres, las relaciones entre el hombre y la naturaleza, así como las relaciones del ser humano para consigo mismo. Estas mutaciones no han dejado de incidir en la esfera de los derechos humanos (Pérez Luño, 1991a y b).

1) En el plano de las relaciones interhumanas la potencialidad de las modernas tecnologías de la información ha permitido, por vez primera, establecer unas comunicaciones a escala planetaria. Ello ha posibilitado que se adquiera consciencia universal de los peligros más acuciantes que amenazan la supervivencia de la especie humana. El desarrollo actual de la industria bélica sitúa a la humanidad ante la ominosa perspectiva de una hecatombe de proporciones mundiales capaz de convertir nuestro planeta en un inmenso cementerio. De ahí, que la temática de la paz haya adquirido un protagonismo indiscutible en el sistema de las necesidades insatisfechas de los hombres y de los pueblos del último periodo de nuestra historia colectiva

Tampoco puede soslayarse que el contexto en el que se ejercitan los derechos humanos es el de una sociedad donde la informática ha devenido el símbolo emblemático de nuestra cultura, hasta el punto de que para designar el marco de nuestra convivencia se alude reiteradamente a expresiones tales como la "sociedad de la información", o a la "sociedad informatizada".

El control electrónico de los documentos de identificación, el proceso informatizado de datos fiscales, educativos y médicos, el registro y gestión de las adquisiciones comerciales realizadas con tarjetas de crédito, así como de las reservas de viajes, representan algunas muestras bien conocidas de la omnipresente vigilancia informática de nuestra existencia habitual. Nuestra vida individual y social corren, por tanto, el riesgo de hallarse sometidas a lo que se ha calificado, con razón, de "jui- 
cio universal permanente". Ya que, en efecto, cada ciudadano fichado en un banco de datos se halla expuesto a una vigilancia continua e inadvertida, que afecta potencialmente incluso a los aspectos más sensibles de su vida privada; aquellos que en épocas anteriores quedaban fuera de todo control por su variedad y multiplicidad.

2) En el curso de estos últimos años pocas cuestiones han suscitado tan amplia y heterogénea inquietud como la que se refiere a las relaciones del hombre con su medio ambiental, en el que se halla inmerso, que condiciona su existencia y por el que, incluso, puede llegar a ser destruido. La plurisecular tensión entre naturaleza y sociedad corre hoy el riesgo de resolverse en términos de abierta contradicción, cuando las nuevas tecnologías conciben el dominio y la explotación sin límites de la naturaleza como la empresa más significativa del desarrollo. Los resultados de tal planteamiento constituyen ahora motivo de preocupación cotidiana. El expolio acelerado de las fuentes de energía, así como la contaminación y degradación del medio ambiente, han tenido su puntual repercusión en el hábitat humano y en el propio equilibrio psicosomático de los individuos. Estas circunstancias han hecho surgir, en los ambientes más sensibilizados hacia esta problemática, el temor de que la humanidad pueda estar abocada al suicidio colectivo, porque como l'apprenti sorcier, con un progreso técnico irresponsable ha desencadenado las fuerzas de la naturaleza y no se halla en condiciones de controlarlas. En estas coordenadas debe situarse la creciente difusión de la inquietud ecológica.

La ecología representa, en suma, el marco global para un renovado enfoque de las relaciones entre el hombre y su entorno, que redunde en una utilización racional de los recursos energéticos y sustituya el crecimiento desenfrenado, en términos puramente cuantitativos, por un uso equilibrado de la naturaleza que haga posible la calidad de la vida.

La inmediata incidencia del ambiente en la existencia humana, la contribución decisiva a su desarrollo y a su misma posibilidad, es lo que justifica su inclusión en el estatuto de los derechos fundamentales. Por ello, no 
debe extrañar que la literatura sobre el derecho medioambiental, derecho y ecología, y el derecho a la calidad de vida constituyan uno de los apartados más copiosos en la bibliografía actual sobre los derechos humanos. Y parece poco razonable atribuir este dato al capricho, o a la casualidad.

3) De igual modo, las nuevas tecnologías han contribuido decisivamente, a posibilitar un conocimiento más radical del propio ser humano. Durante milenios el hombre ha sido un desconocido para sí mismo. Desde la perspectiva de los avances científicos y tecnológicos de nuestro tiempo, no pueden dejar de considerarse como meras elucubraciones ingenuas e insuficientes las teorías y conjeturas rudimentarias, que desde la medicina, la biología, la psicología y la filosofía se venían haciendo sobre el significado y la estructura de la naturaleza humana (cfr.: Casado, 1998; Gracia, 1989)

En los últimos años los avances de la ingeniería genética y la biotecnología han permitido trasladar desde la incertidumbre y la penumbra de las elucubraciones a la seguridad de los datos científicos, el conocimiento de la vida humana. Los estudios sobre el genoma humana y la consiguiente revelación del mapa genético de nuestra especie constituyen un nuevo marco de referencia para el estudio y la propia tutela de los derechos humanos (cfr: Malem Seña, 1995; Porras del Corral, 1996).

Estos progresos no se hallan exentos de riesgos. Es sabido, que la etapa actual de desarrollo biotecnológico, junto a avances y desarrollos indiscutibles, ha generado nuevos fenómenos de agresión a los derechos y libertades. En esas coordenadas se ha generado un movimiento de la doctrina jurídica y de la jurisprudencia de los países con mayor grado de desarrollo tecnológico tendente al reconocimiento del derecho a la $l i$ bertad informática y a la facultad de autodeterminación en la esfera informativa. De acuerdo con lo expuesto en los apartados que integran estas reflexiones, este nuevo derecho tendería a la tutela de la intimidad de los datos sanitarios procesados a través de las nuevas tecnologías; o también de aquellos que tienen su origen en ámbitos de experimentación biotecnológicos. 
En una sociedad como la que nos toca vivir en la que la información es poder y en la que ese poder se hace decisivo cuando, en virtud de la informática, convierte informaciones parciales y dispersas en informaciones en masa y organizadas, la reglamentación jurídica de la informática reviste un interés prioritario, de modo especial, en lo que afecta a datos concernientes a la salud. Es evidente, por tanto, que para la opinión pública y el pensamiento filosófico, jurídico, médico y político de nuestro tiempo constituye un problema nodal el establecimiento de unas garantías que tutelen a los ciudadanos frente a la eventual erosión y asalto tecnológico de su intimidad, así como del resto de sus derechos y libertades.

En la situación tecnológica propia de la sociedad contemporánea, que se apresta a iniciar el curso del Tercer Milenio, todos los ciudadanos, desde su nacimiento, se hallan expuestos a violaciones de su intimidad perpetradas por determinados abusos de la informática y la telemática. La injerencia del ordenador en las diversas esferas y en el tejido de relaciones que conforman la vida cotidiana se hace cada vez más extendida, más difusa, más implacable. Este estudio ha pretendido dar cuenta de esta situación, en la esfera de los datos personales concernientes a la salud, así como de la respuesta jurídica que tal reto entraña. 
BÉJAR, H, (1988): El ámbito íntimo. Privacidad, individualismo y modernidad, Alianza, Madrid.

BING, J. (1980): Personal Data Systems. A Comparative Perspective on a Basic Concept in Privacy Legislation, en "Information Privacy", vol. 2, pp. 28-33.

BRANDEIS, L.D. (1890-91): vid. Warren, S.D.

BRANDEIS, L.D. (1928): Mr. Justice L.D.

Brandeis Dissenting Opinion en el proceso Olmstead v. United States, recogido en Shattuck, J.H.F,(1977).

CABEZUELO ARENAS, A. L.(1998): Derecho a la intimidad, Tirant lo blanch, Valencia

CASADO, M. (1.998): Bioética, Derecho y

Sociedad, Trotta, Madrid.

CIBERAFONDO (2002):

(http://www.ciberafondo/ciberafondo_mundotech_ articulos.php?articulo=2235.ph)

DENNINGER, E. (1967): Rechtsperson und

Solidarität, Metzner, Frankfurt a.M.-

DENNINGER, E.(1987): El derecho a la autodeterminación informativa, trad. cast. de A.E. Pérez Luño, en el vol. col. Problemas actuales de la documentación y la informática jurídica (Actas del Coloquio Internacional celebrado en la Universidad de Sevilla, 5 y 6 de marzo de 1986), a cargo de A.E. Pérez Luño, Tecnos \& Fundación Cultural Enrique Luño Peña, Madrid.

DENNINGER, E. (1995): Verfassungsrecht und Solidarität, en "Kritische Vierteljahresschrift für Gesetzgebung und Rechtswissenschaft", $n^{0}, 1$ pp. 7-24

FROSINI,V, (1982): Cibernética, derecho $y$ sociedad, trad. cast de A. Salguero y R. Soriano, con Prólogo de A. E. Pérez Luño, Tecnos, Madrid.

FROSINI,V, (1986): L'uomo artificiale. Etica e diritto nell'era planetaria, Spirali, Milano.

GARCÍA MORENTE, M, (1992): Ensayo sobre la vida privada (1935) se cita por la nueva ed. de la
Facultad de Filosofía de la Universidad Complutense, Madrid.

GARCÍA SAN JOSÉ, D. (2002):"Notas sobre la Ratificación por España del Protocolo Adicional al Convenio para la Protección de los derechos humanos y la dignidad del ser humano con respecto a las aplicaciones de la Biología y la Medicina, por el que se prohibe la clonación de seres humanos, hecho en París el 12 de Enero de 1998", en Anuario de Derecho Europeo, n'.1 García San Miguel, L, (ed.), (1992): Estudios sobre el derecho a la intimidad, Tecnos, Madrid.

GARRIGA DOMÍNGUEZ, A. (1999): La protección de los datos personales en el Derecho español, con Prólogo de A. E. Pérez Luño, Universidad Carlos III \& Dykinson, Madrid.

GRACIA, D. (1.989):Fundamentos de Bioética, Eudema, Madrid.

HIXSON, R.F, (1987): Privacy in a Public Society, Oxford University Press, New York \& London.

HOHFELD, W. N, (1913): Some Fundamental Legal Conceptions as Applied in Judicial Reasoning, en "Yale Law Journal", vol. XXIII, pp. 16-45 (existe trad. cast. de C. Carrió, Centro Editor de América Latina, Buenos Aires, 1968).

LUCAS MURILLO DE LA CUEVA, P. (1990):El derecho a la autodeterminación informativa, Tecnos, Madrid.

MAIHOFER, W, (1968): Rechtsstaat und menschliche Wïrde, Klostermann, Frankfurt a M.

MALEM SEÑA, J. (1995): "Privacidad y mapa genético", en Isonomía, n. 2.

MARCOS DEL CANO, A. M. (1.999): La eutanasia: estudio filosófico juridico, Marcial Pons, Madrid.

MARTÍN MATEO, R. ( 1.987): Bioética y Derecho, Ariel, Barcelona.

MARTÍNEZ, CAICERRADA, J. (1.986,):Derecho Médico, Tecnos, Madrid, Tomo I. 
MILLER A. (1971): The Assault on Privacy, The University of Michigan, Ann Arbor.

MORALES PRA'TS, F, (1984): La tutela penal de la intimidad, Destino, Barcelona.

O'CALLAGHAN MLÑOZ, X, (1992): Derecho al honor, a la intimidad y a la propia imagen, en la obra col. Los derechos fundamentales y libertades públicas. XII Jornadas de Estudio de la Dirección General del Servicio Jurídico del Fistado,

Ministerio de Justicia, Madrid, vol.I, pp. 543-627.

ODONTORED (2002):

(http://www.odontored.cl/armednet,htm)

ORTEGA Y GASSET, J. (1983): El Espectados-VI; en Obras Completas, Alianza Editorial \& Revista de Occidente, Madrid, vol. 2 ; El hombre y la gente, ibíd., vol. 7 .

OSORIO, L, (1992): Los derechos al honor, a la intimidad y a la propia imagen como límites de la liberiad de expresión e información, en la obra col. Los derechos fundamentales y libertades puiblicas. XII Jornadas de Estudio de la Dirección General del Servicio Jurídico del Estado, Ministerio de Justicia, Madrid, vol.I, pp. 659-689.

PARDO FALCON J, (1992): Los derechos del artículo 18 de la Constitución española en la jurisprudenica del Tribunal Constitucional, en "Revista Española de Derecho Constitucional", n" 34, pp. 141-178.

PARFIT, D, (1979): Prudence, Morality, and the Prisioner's Dilemma, en "The Proceedings of the British Academy", vol. LXV, pp. 539-564 (existe trad. cast. de G. Gutiérrez, Facultad de Filosofía de la Universidarl Complutense, Madrid, 1991).

PÉREZ LUÑO, A.E, (1989): Libertad informática $y$ leyes de protección de datos personales, en colab. con M.G. Losano y M.F. Guerrero Mateus, Centro de Estudios Constitucionales, Madrid.

PÉREZ LUÑ̃, A.E, (1991 a): Las generaciones de derechos fundamentales, en "Revista del Centro de Estudios Constitucionales", n 10, pp. 203-217.
PÉREZ LLÑ̄O, A.F, (1991 b): Le generazioni dei diritti umani, en el vol. col. a cargo de F.

Riccobono, Nuovi diritti dell età tecnologica, (Atti del Convegno tenuto a Roma presso la Libera Università Internazionale degli Studi Sociali, 5 e 6 maggio 1989), Giuffrè, Milano, pp. 139-155.

PÉREZ LUÑO, A.E, (1992 a):Intimidad y proterción de datos personales: del habeas corpus al habeas data, en Estudios sobre el derecho a la intimidad, ed. a cargo de L. García San Miguel, cit., pp. 36-45.

PÉREZ LUÑ̄, A.E, (1992 b): Aspectos de la tutela del derecho a la intimidad en la Jurisprudencia, en la obra col. Los derechos fundamentales $y$ libertades públicas. XII Jornadas de Estudio de la Dirección General del Servicio Juridico del Estado, Ministerio de Justicia, Madrid, vol.I, pp. 709-724.

PÉRFZ LUÑO, A.E, (1993): La LORTAD y los derechos fundamentales, en "Derechos $y$ Libertades", n 1, pp. 405-424.

PÉREZ LUÑO, A.E, (2000): Aspectos y problemas juridicos de internet, en el vol. col., a cargo de Javier de Lorenzo, Medios de comunicación y sociedad: de información, a control y transformación, Consejo Social de la Universidad de Valladolid.

PÉREZ L.UN̄O, A.E, (2001 a): La tutela jurídica de los datos personales en España, en "La Toga" (Revista del Ilustre Colegio de Abogados de Sevilla), $n^{\circ}$ 131, pp. I-XXIV

PÉREZ LUÑO, A. E. (2001 b): Sobre el arte legislativo de birlibirloque. La LOPRODA y la tutela de la libertad informática en España, "Anuario de Filosofia del Derecho" tomo XVIII, pp. 32l-36l.

PÉREZ LUÑO, A.E, (2003): Derechos humanos, Estado de Derecho y Constitución, Tecnos, Madrid;1984, se cita por la $8^{2}$ ed.

PODL.FCH, A, (1984): Art. 2 Abs. 1, en

Kommentar zum Grundgesetz fiur die 
Bundesrepublik Deutschland (Reihe

Alternativkommenta-re), Luchterhand, NeuwiedDarmstadt.

PORRAS DEL CORRAL, M.

(1.996):Biotecnologia, derecho y derechos humanos, CajaSur, Córdoba.

PORTALEY (2002):

(http://www.portaley.com/empresa/revista2404200 2.shtml)

RODRÍGUEZ DEL POZO ÁLVARIJZ,, P. (1994):

"Los derechos de los enfermos", en el vol.

Derechos de las Minorías y de los Grupos

Diferenciados, Escuela Libre Editorial \&

Fundación Once, Madrid.

SÁNCHEZ BRAVO, A. (2001): Internet y la sociedad europea de la información: implicaciones para los ciudadanos, con Prólogo de A.E. Pérez Luño, publicaciones de la Universidad de Sevilla.

SÁNCHEZ CARAZO, C. (2000): La intimidad y el secreto médico, Díaz de Santos, Madrid.

SÁNCHEZ JIMÉNEZ, E. ( 1999): La eutanasia ante la moral y el derecho, con Prólogo de A.E. Pérez Luño, Universidad de Sevilla, Secretariado de Publicaciones, Sevilla.

SÁNCHEZ-CARO J. Y SÁNCHEZ-CARO J. (2001): El médico y la intinidad, Díaz de Santos, Madrid.

SEOANE RODRÍGUEZ, J.A. (2002): De la intimidad genética al derecho a la protección de datos genéticos. La protección iusfundamental de los datos genéticos en el Derecho español ( $A$ propósito de las SSTC 290/2000 y 293/2000, de 30 de noviembre), (Parte 1), en "Revista de Derecho y Genoma Humano", $n^{\circ} 16$, pp. 71-105

SHATTUCK, J.H.F, EDITOR, (1977): Rights of Privacy, National Textbook Company \& American Civil Liberties Union, Skokie (Illinois) - New York.

SIMITIS, S, (1987): Revieuing Privacy in an Information Society, en "University of Pennsylvania Law Review", vol. 135, n 3, pp. 707-746.

TRLYOL SERRA, A Y VILLANUEVA, R, (1975):

Derecho a la intimidad e informática, en

"Informatica e Diritto" ${ }^{\circ}$ l. pp. 171-187.

VITALIS, A, (1981):Informatique, pouvoir et libertés, Economica, Paris.

WARREN, S.D. Y BRANDEIS, L.D, (1890-91):

The Right to Privacy, en "Harvard Law Review", n.4, pp. 193-220.

WESTIN A. (1967): Privacy and Freedom, Atheneum, New York.

WESTIN A. Y BAKER M, (1972): Databanks in a Free Society, Quadrangle Books, New York.

YOUNGER COMMITTEE ON PRIVACY, (1971): Price of Privacy, Privacy Committee of the Society of Conservative Lawyers, London. 